\title{
Recent Trends and Future Tasks in Steelmaking Technology in Japan
}

\section{Mutumi OHJI}

Kimitsu Works, Nippon Steel Corporation, Kimitsu, Kimitsu, Chiba-ken, 299-11 Japan.

(Received on April 22, 1996; accepted in final form on September 9, 1996)

\begin{abstract}
Blast furnace based steel production will remain important in the world in future, according to analyses of the trend in steel production in over the last 30 years.

An outline of the trends in Japanese steelmaking technology during the past 10 years from the viewpoint of (1) improving the quality of steel, (2) greater productivity and (3) responding to environmental problems is discussed.

Based on a recognition of these conditions, future technological tasks are reviewed and comments offered on new aspects such as iron making processes and continuous casting in near net shape. A brief comment on the role of the Japanese steel industry in the future are described.
\end{abstract}

KEY WORDS: converter; electric-furnace; scrap; continuous casting machine; quality; productivity; environmental problem; future tasks.

\section{Introduction}

During the past decade, crude steel production and the continuous casting $(\mathrm{CC})$ ratio has leveled off about 100 million tons, or $95 \%$. The share of electric-furnace steel has increased to a point exceeding $30 \%$ of that products. (Fig. 1) $)^{1)}$

While steel reserves in general society overall are increasing, it appears obvious that recycled scrap will also increase and the steel re-production by electricfurnaces should increase correspondingly. However, this change may not be as rapid as we might expect. Future trends should be viewed globally.

I would like to discuss the trends in the steelmaking process assuming two cases, higher and lower growth rate of the world's steel production. In 2020, the estimated world crude steel production will be some 950 million tons a year in the higher case, and in the lower case some 850 million tons.

Figure 2 shows changes in the world's estimated consumption of various raw materials. The amount of recycled scrap from the general society is estimated by subtracting the amount of home scrap calculated by casting yield, that is closely related to $\mathrm{CC}$ ratio, from the amount of charged iron calculated by crude steel production and its yield. In the 30 years after 1960 , recycled scrap increased linearly. Assuming this linear increase in recycled scrap consumption continues, future pig iron production will increase if the predicted growth of crude steel production is the higher level or will at least remain at the present level if the lower figure holds. The necessity for this new iron source is not expected to decrease.

The potential growth rate of steel production is high in China and East Asia. There are at present expansion plans for several 10 s of million tons capacity. ${ }^{2)}$ A fairly large proportions of companies are planning to expand capacity by adding electric-furnaces. The need for scrap in these areas is expected to increase year after year.

Table $1^{3)}$ shows the world's scrap trade. Only about 40 million tons of scrap is distributed. In the European Union (EU), scrap imports and exports are nearly balanced, and in the US, which is the main scrap exporter

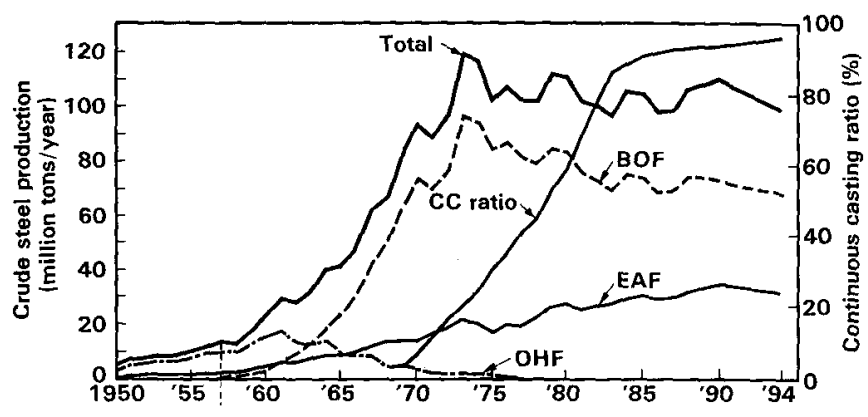

Fig. 1. Change in crude steel production and continuous casting ratio in Japanese steel industry.

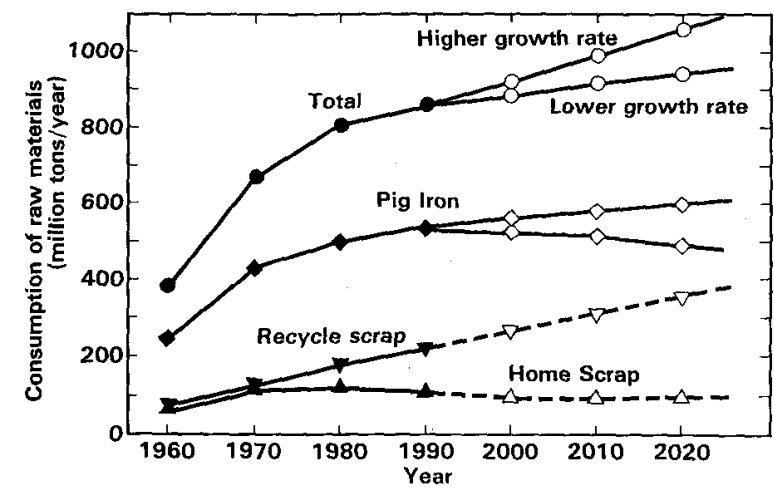

Fig. 2. Change in consumption of raw materials. 
Table 1. Scrap trade in the world (1992).

$\left\{\times 10^{3}\right.$ tons/year $\}$

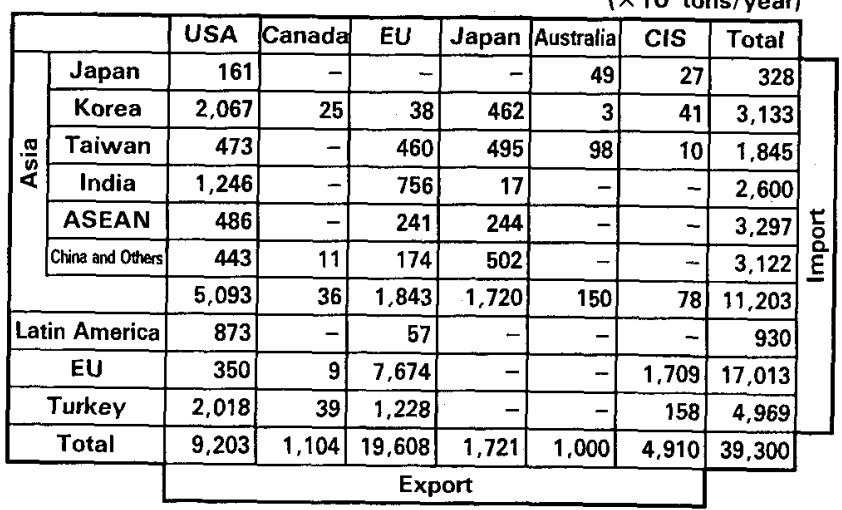

in the world, there are many minimills planning capacity expansion. Therefore, we cannot expect the supply of scrap from the EU and the US to this area. In Japan, imports and exports have recently become nearly balanced, actually exports now exceed imports by a million tons according to the data shown in this table. In Japan alone there will be an overabundance of scrap in the near future. Therefore, it seems probable that Japan will continue to export scrap to East Asia including China.

But from the global point of view, we would rather suffer a scrap shortage. I believe that Japan's capability to produce new iron will continue to make a great contribution to the world's steel production just as it does today. I also feel that an industry having blast furnaces should continue its efforts to improve its own productivity with confidence.

A survey of Japanese steelmaking technology during the past 10 years shows that numerous new and important technologies have been created to raise productivity and to assure high product quality.

I would like to outline the trends in Japanese steelmaking technology for (1) improving the quality of steel, (2) improving productivity and (3) responding to environmental problems.

Recognizing the above existing conditions I would also like to touch upon future technological tasks.

\section{Processes and Operational Technologies Producing High Quality Steel}

\section{(1) Sheet for Automobiles}

There are two requirements to meet customer demands: 1) rust prevention and 2) improved formability. The coating of sheets and the increased coating weight to improve corrosion resistance are factors worsening formability, we have to rapidly advance the application of interstitial free steel (IF steel). The carbon content has been decreased annually to improve formability. ${ }^{43}$

Various RH technologies for stable refining of extralow-carbon steel have been developed and commercialized to cope with the increase use of IF steel and reduction of $\mathrm{C}$ content. These include expanding the snorkel and increasing the argon gas flow rate, for injecting argon gas into the vessel and for injecting oxygen or fuel using a top-blowing lance to prevent the
Table 2. Technologies for the prevention of inclusion defect in slab caster.

Tundish
- Enlargement
- Prevention of reoxidation(sealed)
- Heating
Mold

- Improvement of level control by the modern control theory

- Flow control of molten steel by electromagnetic power

- Improvement of mold oscillation

Profile

- Curved type $\rightarrow$ Vertical bending type

contamination of skull. ${ }^{5)}$

To prevent surface defects on steel sheet of IF steel, various technologies for controlling inclusions in $\mathrm{CC}$ were developed. (Table 2)

(2) Plate Materials: the Case of Line Pipe

As the object of development moved to a severer natural environment in oil development, quality requirements for line pipe became stricter. ${ }^{6)}$ In addition to higher strength, low-temperature toughness and anti-sour-gas properties are required. Requirements for steelmaking are extra low phosphorus, sulfur, oxygen and reduced segregation.

So-called divided refining was introduced to meet these requirements, which involves hot metal dephosphorization, desulfurization in secondary refining by a ladle furnace (LF) or powder injection under vacuum. The adoption of hot metal pretreatment proved to be effective not only for producing quality steel with low phosphorous content but also reduced cost and improved converter productivity.

The author's own area of study changed from the prevention of macro segregation to that of semi-macro segregation, and the technology progressed from conventional strand electromagnetic stirring to soft reduction. The casting conditions vary according to the company. If indicated in terms of reduction per unit time, the optimum reduction rate is almost the same for all companies and ranges from $0.75-0.90 \mathrm{~mm} / \mathrm{min}^{7}{ }^{7}$

\section{Improvement of Process and Labor Productivity}

\section{(1) Refining Technology to Improve Productivity}

During the past 10 years, converter steelmaking time has shortened. While the blowing time remains almost the same, the non-blowing time has been decreased because the killing time is shortened by better blowing accuracy owing to hot metal pretreatment.

This improved converter productivity accelerated the concentration of production on steelworks having large converters. Over 15 years, about 30 converters, most of them with a capacity of less than $200 \mathrm{t} /$ heat were shut down and the average capacity increased by 20 tons/ heat. ${ }^{8)}$

For converter labor-saving technologies, automation of blowing operations of sampling and tapping operations were promoted. This decreased the standard personnel arrangement from 5 to 3 men/converter.

The labor productivity of converters has been nearly 
doubled by the combination of shortened steelmaking time, converter enlargement and labor-saving technologies.

(2) Continuous Casting Technology to Improve Productivity

$\mathrm{CC}$ machines were introduced over a relatively short time span, and were all constructed to have nearly the same performance. The rise in labor productivity was thus promoted rather by additional labor-saving equipment than by any improvement in casting speed. At the most advanced slab machine the total number of operators is only four. Even at relatively old machines, it is possible to realize the same personnel arrangement as the most advanced one.

There have been good advances in the technology for process productivity with commercialization in: 1) extra-high speed changing of slab width, ${ }^{9}{ }^{2}$ 2) the shortening of casting preparation and completion of casting without decreasing the withdrawal speed at the cast end ${ }^{10)} 3$ ) the repetitive use of tundish by repairing in a hot condition greatly advanced. The combination of above mentioned three technologies will be the definite solution in order to cope with the various problems for casting sheet qualities in conventional CC machine.

\section{Technology to Respond to Environmental Problems}

The government has enacted laws concerning recycling and the environment such as the recycling law in 1991, which stipulates that iron and steel slag should be recycled as a by-product of the steel industry.

About 12 million tons of slag is discharged every year. Figure 3 shows changes in the methods of utilizing steelmaking slag. The recycling ratio has been improved to $90 \%$. Relatively stable application of slag such as recycling in steelmaking itself, road construction and cement production is about $30 \%$. However, $50 \%$ of all steelmaking slag is recycled for civil projects for which the demand is unstable and fluctuating. ${ }^{11)}$

Slag utilization activities are strengthened by accelerated aging with steam, and use of magnesium in place of soda ash as desulfurizing agent is making the utilization of slag easier.

\section{Future Technical Tasks}

Recently the new technology is being commercialized such as minimills with compact strip process. To the end of this lecture I would like to make some comments for these new technologies.

\section{(1) Refining Process}

The simplest way to melt scrap is the conventional electric-furnace, provided that supply of high quality scrap is sufficient. This depends on the future trend in world crude steel demand. The ambitious expansion plans of the steelmaking industries in East Asian countries make shortage of scrap highly probable, and the need for new iron will be intensive.

Various ironmaking processes than the blast furnace have been proposed, and are partially commercialized. ${ }^{12}$ But their production capacity is scarcely 1 million tons

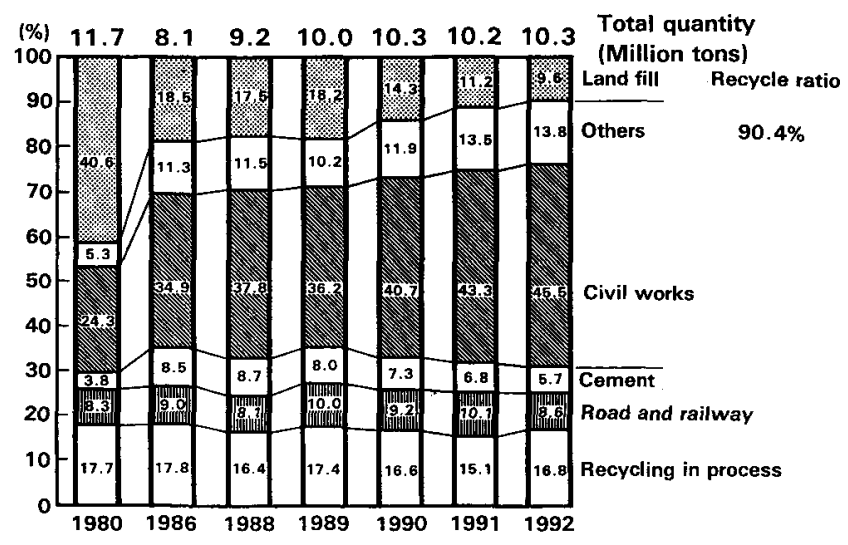

Fig. 3. Uses of steelmaking slag in Japan.

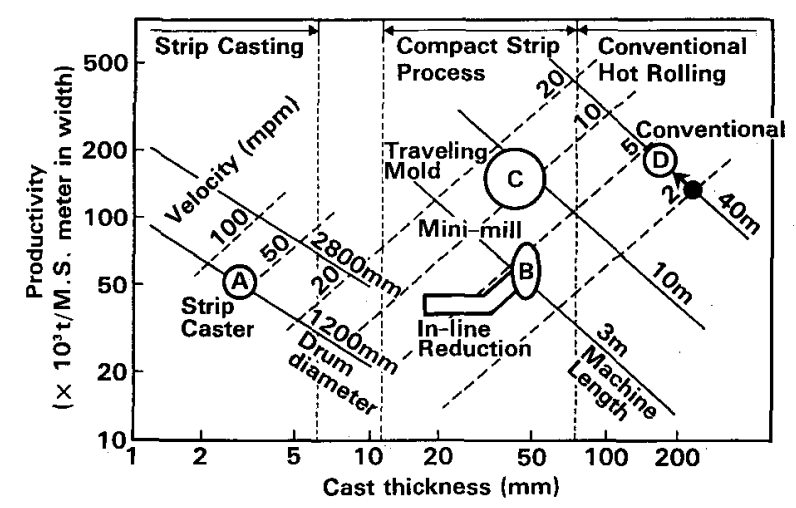

Fig. 4. Position of various casters,

per year. It does not seem they will be able to surpass the blast furnace process in either production capacity, operating cost or energy consumption. Therefore, they will remain complementary processes for new sources of iron for the world, although their development and study is anticipated.

\section{(2) Continuous Casting Process}

It is highly possible that $\mathrm{CC}$ in near net shape will be developed further.

Figure 4 shows the position of various $\mathrm{CC}$ processes. The application of strip casting machines will be limited to stainless steel and other special steels because its productivity is about 500 thousand tons/year in principle. ${ }^{13)}$

The thin slab caster has been successfully commercialized by the compact strip process, which opened the new entry for the strip business, with relatively small production capacity and at the same time with relatively small investment. This invention provides easy application of relatively small scrap melting process (i.e. electric furnace process) to the field of conventional integrated steel complex.

The traveling mold has a long history of development and has undergone various trails, but it has not yet reached the commercial stage. Once commercialized, however, this type of thin slab caster will promise high possibilities and effectiveness. The combination of this type of thin slab caster and a compact strip process will be able to replace the conventional process even at the production scale of over 2 to 3 million tons a year. 


\section{Conclusions}

In this lecture, it has been discussed that the blast furnace based steel production will remain important in the world in future, according to the analysis of the trend of steel production over the last 30 years. I have reviewed the continued technical challenge by Japanese steel industry for higher quality, greater productivity and environmental protection. Finally, I would like to conclude with a brief comment on the future role of Japanese steel industry.

At the moment the Japanese steel industry seems to be suffered from the great appreciation of the Yen and from global competition in the international open market. But even under these circumstances the challenge for the Japanese steel industry is still the same, that is, the development of the technology aiming higher quality and productivity. It is absolutely necessary for Japanese steel industry to be able to survive in global competition.

At the same time it is our task to prepare the future technologies which will be necessary for the coming East Asian steel industries. I am convinced, we, Japanese steel industry, have developed the concept of modern integrated steel works regarding the production scale, production facilities, operational technologies and so on. On the other hand, we owe many basic technologies such as oxygen converter, continuous caster, and even quality control system, to the steel industries of the US and

\section{European countries.}

Now I think, it is our responsibility to hand over these new steelmaking technologies to the steel industries of rising East Asian countries which eventually need them in future.

We would like to continue our effort for a technological breakthrough with an eye always kept on a global growth of the steel industry.

\section{REFERENCES}

1) M. Ohji: The 153rd-154th Nishiyama Memorial Seminar, ISIJ, Tokyo, (1994), 1.

2) H. Toyota: The 27th-28th Shiraishi Memorial Seminar, ISIJ, Tokyo, (1994), 144

3) M. Koyama: The 27th-28th Shiraishi Memorial Seminar, ISIJ, Tokyo, (1994), 40.

4) M. Ohji: Tetsu-to-Hagané, 78 (1992), 1628.

5) H. Takeuchi: Tetsu-to-Hagané, 81 (1995), 290

6) M. Ohji: The 153rd-154th Nishiyama Memorial Seminar, ISIJ, Tokyo, (1994), 7.

7) M. Ohji: The 153rd-154th Nishiyama Memorial Seminar, ISIJ, Tokyo, (1994), 20.

8) H. Yamana: Tetsu-to-Hagané, 81 (1995), 295.

9) M. Tenma, S. Hirohama, T. Ninomiya, W.Ohhashi, A. Matushita and K.Tutumi: Tetsu-to-Hagané, 71 (1985), S149.

10) K. Sekino, K. Hanasaki, J. Mitani, K. Yoshida and T. Yokai: SUMITOMO METALS, 45-3 (1993), 86.

11) S. Ikeda: Tetsu-to-Hagané, 81 (1995), 311

12) D. Kaneko: Tekkou-kai, (1995), February, 21.

13) M. Ohji: The 153rd-154th Nishiyama Memorial Seminar, ISIJ, Tokyo, (1994), 34. 